\title{
Expanding the Measure of Congruency: Presidential Anticipation of Public Preferences, 1953-2001
}

\author{
Brandon Rottinghaus
}

Several important studies have examined congruency between presidential policy position taking and public opinion. Much of this policy-public opinion scholarship, however, explores reflexive responsive pathways between representative and represented, where presidents read public opinion and respond to the opinions of the known public. A less explored aspect of presidential responsiveness to public opinion is the idea of presidential anticipation of future public opinion similar to Key's (1964) concept of "latent opinion." In this article, we offer a simple measure of anticipatory public opinion. Confirming what Key speculated about latent opinion, we find that presidents are more likely to successfully anticipate public preferences when the issue is salient and when elections are approaching, whereas popularity matters very little. Based upon these findings, presidents tend to look outward at the future political environment they face rather than inward (at current popularity) in anticipating reactions to new policy agendas.

Decades of research have demonstrated that public opinion has a consistent effect on the design of public policy. ${ }^{1}$ Specifically, these scholars find connections between public opinion and public policy outputs between half to three-quarters of the time (Page and Shapiro 1983; Stimson et al. 1995; Monroe 1998; Burstein 1998; Erikson et al. 2002). At the federal level, public opinion has been demonstrated to have a positive effect on spending, for instance, across a range of issues (Wlezien 1995), health care policy (Jacobs 1993), defense policy (Hartley and Russett 1992; Wlezien 1996) and welfare (Fording 1997). Much of this policy-public opinion scholarship, however, explores reflexive responsive pathways between representative and represented, where presidents read public opinion (through polls and otherwise) and respond to the opinions of the public.

A less explored aspect of presidential responsiveness to public opinion is the idea of presidential anticipation of public opinion. ${ }^{2}$ Anticipation of public opinion occurs when politicians anticipate public opinion in the future and adopt policy positions (often new policies) without perfect information on whether or not the public will approve, or "where politicians try to please future voters" (Mansbridge 2003, 517). Anticipation of public opinion arises from politicians' desire to get reelected and implies politicians are continually reflective of public preferences (Arnold 1993). The presumption is that voters punish (or may punish) politicians for policy positions taken outside the boundary of public opinion and these voters use retrospective frames to 
evaluate success (Page 1978). Anticipation of opinion is also theoretically akin to presidents anticipating what effect their actions will have on the electorate, a concept Key (1964) refers to as "latent" opinion. Key defines latent opinion as opinion that is "hibernating" but "given relevant or appropriate stimulus, the opinion will be triggered into expression or action" $(1964,264)$. This conceptualization of public opinion is a realistic approach to studying public opinion because, if we assume politicians are concerned about public standing and reelection, latent opinion is the "type of reaction that governments must be concerned about as they weigh the possible effect of events on public opinion" (Key 1964, 274).

Scholarly work exploring the degree to which presidents read and react to public opinion (after that opinion has been formalized in a poll or otherwise, most often called opinion congruency) gives us only one dimension of how presidents take policy positions. To remedy this, the goal of this article is to provide an initial simple and direct test of the concept of anticipatory opinion by utilizing data that directly measure presidential congruent position taking on future favorable public opinion. We measure latent opinion by creating a large data set of matched presidential statement and public opinion polls - if there was no valid public opinion on the president's statement within one year before the date the president made the statement but a majority of the public (51\% or greater) agreed with the statement after the statement was made, the president successfully "anticipated" latent public opinion. We link the literatures of congruent position taking and latent opinion by testing several theoretical assertions concerning the practice of anticipation of latent public opinion, including temporal aspects, electoral connections and issue dynamics. Doing so will extend analysis of presidential responsiveness to public opinion and aid our explanation of the behavioral parameters of the public presidency.

Indeed, presidential anticipation of public opinion and Key's compelling concept of "latent opinion" can help us understand the degree to which presidents anticipate public opinion and take policy positions accordingly. ${ }^{3}$ Studies about activation and anticipation of latent opinion also have potential to influence our understanding of congruent position taking, yet few works have undertaken this task. Zaller hints at a "revival" for latent opinion and suggests that this topic "ought to be more central to the study of public opinion than it is" $(2003,312)$. Indeed, Key argues, "the concept of latency of opinion enables us to elaborate this model of the relation between government and opinion" $(1964,282)$. As noted, however, we do not fully know the extent to which presidential actors are successfully able to guess, reason or infer future public opinion. This approach allows for us to understand how and when politicians attempt to be responsive (or not) to public opinion and expands our scholarly understanding of presidential responsiveness to public opinion. 


\section{Anticipating Latent Opinion}

The concepts of anticipatory and latent opinion have practical and scholarly value in the discussion of the implications of public opinion on policy making. As noted, Key describes the concept of latent opinion as opinion that exists but has yet to be manifest into active opinion, yet "given relevant or appropriate stimulus, the opinion will be triggered into expression or action" $(1964,264)$. Key's clever explanatory analogy relates a story of a burglary in a neighborhood where a certain level of hostility may exist towards the burglary, but "the opinion remains latent until, say, a wave of burglaries sets off a movement to oust the chief of police" $(1964,264)$. Key suggests that "anticipation" of future public preferences is important to politicians because "attentive" citizens are "equipped with ingrained sets of values, criteria for judgment, attitudes, preferences, dislikes - pictures in his head - that come into play when a relevant action, event or proposal arises" $(1964,264)$. As a result, politicians must carefully weigh the presumed future expectations of public support in taking new policy or political positions.

Latent opinion is estimated by politicians based upon response propensities and past routines that the public has followed in reaction to particular past events. Key notes that these responses from the "attentive public" engage "patterns of reaction that serve as bases for predictable responses" that are "more or less Pavlovian" and are linked to "the broad kinds of values and expectations held by people" and by their willingness to absorb elite cues $(1964,265,271,274)$. Zaller similarly agrees that these propensities to event stimuli are predictable and that seasoned politicians "learned or could at least sense many of these propensities" in order to reason their way to reelection $(2003,314)$. Zaller (2003) specifically lists economic events and "rally around the flag" events as periodic, routine events that activate latent opinion. Therefore, presidents must understand these opinion "stimuli" and make anticipatory determinations when designing and unveiling policy positions that are congruent with future public opinion. Fundamentally, then, latent opinion represents the prospect for "future congruence" (or the degree to which presidents anticipate what the public will want and take positions accordingly) and can therefore be linked to other concepts involving presidential congruence with public opinion.

\section{Testing Anticipation of Opinion}

The parameters of presidential anticipation of opinion (and latent opinion) produce two prominent, simple and testable conditions under which we might expect presidents to anticipate public opinion: elections and important issues. Both political phenomena constrain presidential action by forcing the 
president to acknowledge and predict future public preferences because the public is more likely to notice if presidents are not responsive during these times or on these issues. Presidents are uncertain about future votes and are therefore constrained by these political and temporal forces, both of which have the effect of drawing closer attention and scrutiny on presidential actions, to coordinate their action with public opinion. Thus, in order to test Key's assertions about latent opinion and determine under what conditions presidents find success at anticipating opinion, we offer five hypotheses to more fully flesh out these two broad themes.

\section{Elections}

Given the critical linkage of contemporary judgments about public opinion and the next election in successfully anticipating opinion, election years serve as critical political considerations (see Mansbridge 2003). Given the partially prospective nature of elections, we should expect presidents to be more successful in anticipating public opinion in election years because presidents are worried about appearing non-responsive to the public during a time where there is a possibility of not getting reelected. Scholars have found similar patterns in other responsive environments. For instance, presidents are found to be responsive to previous public preferences when an election is imminent or when a policy position is seen to be favorable in terms of leadership image (Canes-Wrone et al. 2001, Canes-Wrone and Shotts 2004; Rottinghaus 2006). Scholars have also found these patterns when exploring legislative behavior (generally in the U.S. Senate since the unit of analysis is greater), specifically that Members of Congress more closely adhere to known median voter preferences when elections are coming soon (Kuklinski 1978; Elling 1982; Thomas 1985).

Further, latent opinion is intimately linked with what Key terms "electoral reprisal." Consistent with our theorizing above, he notes "anxieties about electoral reprisal doubtless condition the operations of democratic governments" $(1964,268)$. The president, he argues, should be especially interested in the consequences of his actions on public opinion since latent opinion may become activated and thereby significantly affect his chances for reelection. The end result of "activated" latent opinion is the conversion of amorphous latent opinion into votes. Key notes, "latent opinion may not be truly activated until it is converted into a vote in appraisal of those who make public decisions. Estimation of latent opinion in this sense becomes the tricky job of forecasting the relation of particular actions and events to future popular votes" $(1964,267)$. Presidents are therefore more likely to anticipate public preferences with congruent position taking or unveiling popular policies especially when elections are closer. And, in theory, second 
term presidents, who vacate this pressure, are less likely to anticipate public preferences in their second terms.

Alternatively, because of the futuristic nature of latent opinion, we should also expect that presidents are less responsive to previous election outcomes in generally engaging in anticipatory responses to opinion than a prospective judgment about public preferences in the future. Electoral data can give meaningful signals to presidents about the policy preferences of the public (Kelley 1983; Conley 2001). However, the structural determinants of successful anticipation of public opinion are not based on "promissory" representation (where presidents promise policy or political action during an election and work during their term to accomplish that goal, see Mansbridge 2003), but rather a forecast of what the voters will want in the subsequent election. Therefore, measures of the percentage of the popular vote garnered in the previous election should result in a negative association with successful anticipation of public opinion.

Election Year Hypothesis: Presidents will be more successful at anticipating public opinion in election years.

Prior Vote Hypothesis: Results from previous elections (percentage of the popular vote received) should be a negative indicator of anticipatory behavior.

Second Term Hypothesis: Given the election-based behavior of first term presidents, presidents in their second terms should not be as reflective of future public opinion.

\section{Issue Salience $^{4}$}

The second broad condition thought to enhance presidential anticipation of opinion is the importance (or prominence) of an issue. The parameters of the public presidency generally foster in presidents an incentive to talk about issues that are most salient in the public's mind, particularly if administrations are concerned with at least appearing responsive to public concerns (Cohen 1999). Presidents may also adapt this strategy depending on the nature of the issue. Scholars have found that presidents are more responsive on "pocketbook" issues (those issues that directly affect the public) (Canes-Wrone and Shotts 2004). Similarly, Key argues that elements of public policy that intimately affect the public are more likely to activate latent opinion-specifically, Key notes "economic deprivation, external threat, grave injustice" and "the triggering effect of circumstance may certainly be reinforced by the oratory of those politicians who come forward with diagnoses and prescriptions" $(1964,270)$. If the president reasons that 
the public believes the issue important, the president is more likely to take a position they believe to be congruent with the public or introduce a policy they believe will find favor with the public because the public is paying attention on that issue and can more readily hold the president accountable.

Given the relatively short duration of a president's term and the concurrent need to maximize support at the next election, presidents should be theorized to have "strong incentives" to anticipate the reactions of the public when the public is paying attention (Page 1978). For instance, Stimson et al. find that government officials sense movements in public opinion and "like antelope in an open field, they cock their ears and focus their full attention on the slightest sign of danger" $(1995,559)$. Without perfect information (even with internal White House polling) about exactly what the public will favor (or be aroused to favor) and how future opponents will craft opposing messages, rational presidents are wise to anticipate public opinion under conditions where the public is paying attention, such as when the issue is of a greater perceived importance (see Arnold 1993 and Geer 1996).

Furthermore, presidents desiring to maximize their future popularity with the public will want to talk about issues they speculate might be most salient in the public's mind in the future by taking policy positions on those issues that they predict will resonate positively with the public (Edwards et al. 1995). Similarly, Geer argues that rational politicians are judicious in choosing which non-salient issues to make salient (by discussing them publicly). He finds that choosing policies which are already salient in the public mind is a case of "easy Wilsonian" leadership (1996, 113). Presidents may also seek to anticipate future opinion to transform a popular issue into "their" signature issue (captured by our anticipation measure) by unveiling a new policy proposal or taking a new political position that connects to a public event or crisis. Specifically, Key argues that the kinds of events that stimulate latent opinion are "usually objective conditions that affect or capture the attention of the masses of people" $(1964,270)$. Accordingly, we should see presidents anticipating public opinion on more salient policy or political issues.

Avoiding issues that will impose additional costs on voters is also part of successfully anticipating future public preferences. Arnold argues that "legislators are more fearful of electoral retribution when they consider proposals that would impose large and direct costs on their constituents" whereas those imposing only small costs (or hidden costs) are too narrow to be understood $(1993,411){ }^{5}$ In particular, he argues that most legislators are unwilling to entertain raising the gas tax, cutting Social Security or closing military bases because of perceived retribution at the polls. Further, in-depth legislative studies of tax, energy and economic policy, illustrate that legislators were reluctant to enact policies that imposed direct costs (in the form 
of higher energy prices or tax burdens) on the public (Arnold 1990). Therefore, we should expect presidents to not anticipate congruent public opinion more frequently when the issue in question will impose (or is perceived to impose) a direct cost on the electorate.

Issue Importance Hypothesis: Presidents should anticipate public opinion more when the current salience of the issue is greater, especially if those issues involve matters of interest to voters' pocketbooks.

Issue Cost Hypothesis: Presidents should not anticipate public opinion more when the issues in question potentially impose greater costs on the public.

\section{Measuring Matched Rhetoric and Anticipatory Opinion}

Woodrow Wilson argued in his famous "Leaders of Men" speech that "interpretation" of public preferences is critical to leadership in the presidency. Wilson writes, "Leadership, for the statesman, is interpretation. He must read the common thought: he must calculate very circumspectly the preparation of the nation for the next move in the progress of politics" (Wilson 1890 [1952], 42). Wilson continued, "it need not pierce the particular secrets of individual men: it need only know what it is that lies waiting to be stirred in the minds and purposes of groups and masses of men" (Wilson 1890 [1952], 23, emphasis added). At the core of Wilson's "interpretation" is judgment about public reactions to the president's latest policy agenda and the question of whether or not that policy agenda will meet with mass approval. Wilson's analysis presciently summarizes the concept of how presidents anticipate opinion.

To approximate Wilson's framework for leadership and explain "latent opinion," the specific approach used here was to match presidential policy statements to public opinion with a random sample of total pages from the Public Papers of the President from Presidents Eisenhower to Clinton. ${ }^{6}$ For each page, the first statement of policy expressed on that page was taken as the dependent variable for that case and recorded. ${ }^{7}$ These statements reflect a number of characteristics (or absence of certain characteristics), but the goal of this search was to record a specific policy statement. Because the Public Papers included a large number of statements, several criteria were created for what constituted a valid policy statement on each page. An item was considered valid if it came from the President (not subordinates or other actors) and advocated action on a specific policy. ${ }^{8}$ A vast majority of the president's statements were straight-forward enough to easily code the policy and 
presidential preference. For example, President Clinton saying "I stand by my decision to send troops to Haiti" or "I applaud the efforts of the Republicans in Congress in passing minimum wage increases" both present a clear indication of policy and preference. However, it is likely that pollsters poll on the most salient issues of the day and subsequent to a president speaking on an issue, pollsters may decide to poll on that very issue reasoning that it has entered the public discourse (explaining the "post" only poll). This possible bias excludes our ability to claim presidents "created" this opinion, instead this simply limits our conclusion to claim that presidents correctly reasoned that the policy would be popular by some form (poll, personal interactions, guessing).

The online polling archive at the Roper Center for Public Opinion Research at the University of Connecticut was used to search for public polling data that could be matched to randomly selected presidential policy statements. ${ }^{9}$ The Roper Center has a comprehensive archive of publicly available polls dating back to 1930 and is the most complete record of all public opinion polling available to researchers. This search strategy limits our findings to the issues on which public pollsters poll, narrowing the kind of opinion we can measure and, concurrently, the types of statements we can match. ${ }^{10}$ Ultimately, the issues most frequently registered were large-scale policy issues, allowing us to satisfactorily claim to have covered most of the policy landscape. An examination of the data offers face validity in that Presidents tend to discuss the significant policies one would historically expect them to discuss (e.g., Eisenhower on the farm program and the Korean War, Kennedy on the missile gap and civil rights, Johnson on Vietnam and civil rights, Nixon on Vietnam, busing and federalism, Ford and Carter on energy policy and the crisis in the middle east, Reagan on the Strategic Defense Initiative and tax cuts, Bush on the Gulf War and Clinton on balancing the budget and education reform). This approach also satisfies Zaller's notion that systematic evidence in testing the emergence of latent opinion requires that the issues examined span multiple cases $(2003,333)$. Polling data was searched for one year after the statement on the assumption that public opinion may not rapidly respond to external events, including a president's speech $^{11}$ In each instance, the closest poll to the statement found was coded. $^{12}$

Presidents anticipate future favorable majority opinion (or "activated" latent opinion) when they make an educated guess, rely on internal opinion data or simply use their intuition to take a position on an issue that they expect the public to favor (see Stimson et al. 1995; Mansbridge 2003; Cohen and Hamman 2003). ${ }^{13}$ New policy agenda initiatives are often anticipatory, born out of a political need for support on a particular issue or spawned from new presidential policy initiatives (Light 1999). Likewise, Geer notes that in 
"Wilsonian" leadership, the task of the president is to "give life to such [non-salient] issues" $(1996,47)$. Therefore, as illustrated in Figure 1, presidents sense the contours of opinion (on which they have little certain information) and make a statement they believe will find favor with majorities of the public at the time of the next election. Post-statement polling serves as our measure of the degree to which future publics approve of the president's message. However, we cannot measure the degree to which the White House is "crafting talk," thereby shaping this opinion (Geer 1996; Jacobs and Shapiro 2000), since there is no way to quantify this in the aggregate. We assume this is happening but are limited in this measure to determining the congruence presidents find with public opinion.

In order for a statement to be coded as successfully "anticipatory" of activated latent public opinion, there had to be no valid public opinion on the president's statement within one year before the date the president made the statement but a majority of the public (51\% or greater) had to agree with the statement after the statement was made. Although Key never strictly defines how latent opinion should be measured, this is a reasonable measure of latent opinion and comports on face with Key's (1964) analysis of latent opinion as opinion that exists below the surface but is waiting for an external event (in this case, the president's speech or related action) to excite it. ${ }^{14}$ In our article, measuring public opinion only after a president's statement allows for a valid test of anticipatory opinion because it offers a prospective evaluation of what the public will support and demonstrates the president introducing a new policy to an uncertain political environment (even with the benefit of internal polling). The average number of days from the president's statement to a measured poll is 122 days. As a specific example of successful anticipation of a policy proposal, on October 10, 1963, President Kennedy introduced a policy where the United States would sell excess grain to the Soviet Union. On October 16, a poll was taken in which 59 percent of the polled public agreed with the president on this issue (with no poll one year on the issue prior to the October 16 poll). A sample of emerging policy issues captured include: the Peace Corps (Kennedy), the Civil Rights Act of 1964 and the Voting Rights Act of 1965 (Johnson), block grants to

Figure 1. Simple Model of Anticipation of Public Opinion

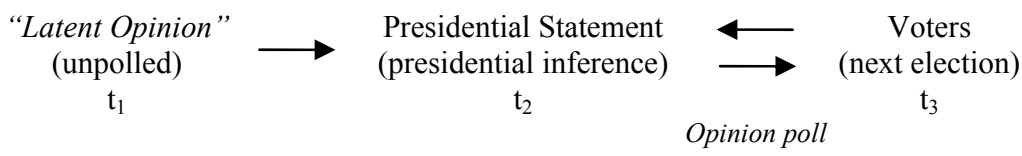

Note: Voters represent voters at the time of the next election, where the president's statement simultaneously anticipates voters' reactions and is shaped by inferred reactions (see Mansbridge 2003). 
the states (Nixon), negotiations over the peace agreement between Israel and Egypt (Carter), the Strategic Defense Initiative and the space shuttle program (Reagan) and AmeriCorps, the "Don't Ask, Don't Tell" policy and the Family Medical Leave Act (Clinton). In addition, several instances captured "new" policies related to unexpected foreign interventions, including sending troops to the Dominican Republic (Johnson), the Middle East (Carter) and Iraq (Bush).

This measurement provides us with assurance that if we find a statement-poll match after the president's statement, that there was no such pollregistered opinion on the issue before the president spoke. This measure implies that the opinion registered in the "post-speech only" poll has been "excited" by the president's speech (and related events), consistent with our understanding of latent opinion and "Wilsonian" leadership. A poll was considered pertinent if the specific policy statement expressed in the Public Papers was the same policy expressed in the public poll. Great care was taken to search all of the germane polling data to ensure that the policy expressed in the president's statement matched the policy in the poll. Occasionally, the president would not express a specific solution or viewpoint on a policy but would offer a vague statement about the importance or urgency of the problem. If this was the case, and no policy poll could adequately be matched to the statement, only the salience of the measure was coded. Overall, this matching process left 230 cases where an opinion poll was found only after the president's statement, allowing us to measure anticipatory congruency in these cases. ${ }^{15}$

This measurement also assuages several concerns about imprecise measures of public opinion and advantageously provides a continuous and analytically distinct measure of anticipatory opinion. Several studies discuss "anticipation" of public opinion (see Canes-Wrone 2006, 6), but this definition can be used to encompass several kinds of behavior. In addition, presenting an "after only" design "becomes useful information in assessing the degree of the aggregate shift in the public mood" and allows for analysis of the degree to which a president's new policy agenda is received by the public (Cohen and Hamman 2003, 147). In fact, Key (1964) initially tests his theory about latent opinion with a similar quasi-experiment (event and opinion measure test). Finally, this allows us to examine a random and continuous (throughout the president's term) selection of policy issues on which presidents take positions, not simply those in State of the Union messages (Cohen 1999) or on budget proposals (Canes-Wrone 2006), position taking which might bias the results in favor of finding significant anticipatory success. 


\section{Model and Findings}

The bivariate data demonstrate that presidents from Eisenhower to Clinton are generally adept at anticipating future majority favorable opinion with their policy statements, and most presidents are able to do so 75 percent of the time. ${ }^{16}$ Put more simply, presidential rhetoric successfully takes positions on issues that are likely to be favored in the future by the public in most situations. Thus, contradicting Key's (1964) assertion, presidents are relatively good at anticipating unformed, future public opinion. Yet, to model a causal multivariate relationship, Table 1 identifies two OLS models with the percent approving of the president's policy after the president spoke on it (measured continuously). ${ }^{17}$ Other probabilistic models, including a Heckman model, were analyzed and rejected because (1) dichotomous measures of the dependent variable (successful anticipation of popular opinion or not) over fit the data by squeezing the total percentage approval into a dichotomous variable and (2) the inverse Mills ratio (lambda) for several specifications of the Heckman model were not significant, indicating no need to use a censored model. ${ }^{18}$ To control for any endogenous influence, we also include a variable representing a president's policy promise in the most recent past State of the Union message, which effectively models a "control variable" to control against presidents taking positions on a range of issues (see Canes-Wrone 2001; 2006). ${ }^{19}$

In both OLS models in Table 1, the three election-related variables were statistically significant predictors (holding all other factors constant) of presidential statements anticipatory of "activated" latent opinion, largely confirming our overarching expectations about the role of elections in harnessing latent opinion: the percentage a president won in the popular vote (Popular Vote), which was negative, and the closer in time until the next election (Election Year Distance), which was positive, and presidential election year (Presidential Election Year), which was positive. ${ }^{20}$ As expected, anticipation of latent opinion is inherently a forward-looking enterprise; thus it makes sense that an impending presidential reelection (or possible election of a party standard bearer), as the primary motive for the White House, drives behavior rather than backward-looking behavior.

Specifically, our predictions in the Election Year Hypothesis and Prior Vote Hypothesis were proven accurate. We argued that presidents would be more anticipatory in election years where the president was at the top of the ticket. Table 1 indicates that the coefficient for presidential election year is strong and statistically significant for both models $(.274, .237)$. Further, the variable "countdown" code for election year approaching ("Election Close") captures a measure of presidential behavior leading up to the election year. Again we find this election forecasting variable strong and significant in 


\section{Table 1. Factors Predicting Successful Presidential Anticipation of Latent Opinion}

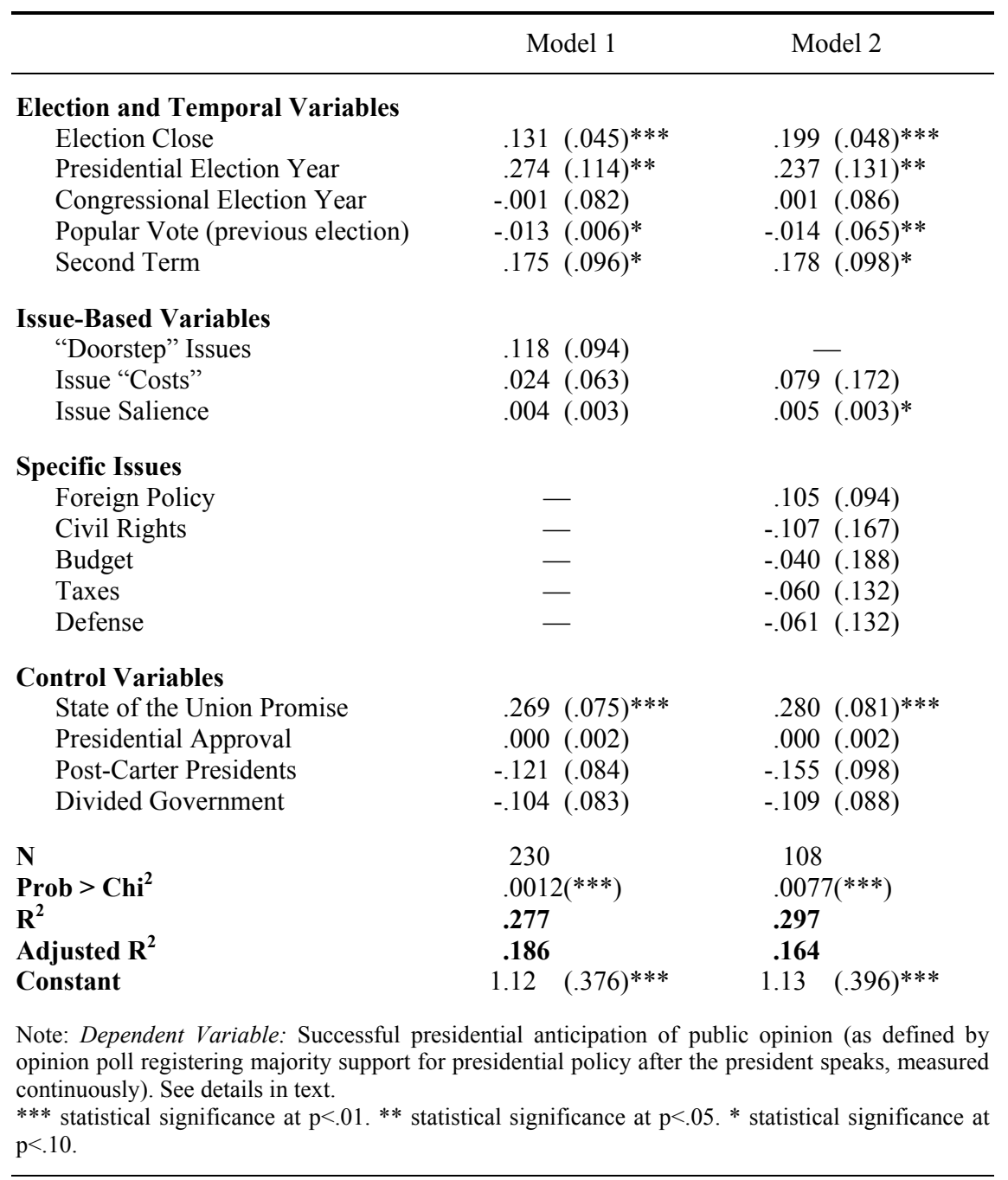

both models $(.131, .199)$. These findings largely comport with studies demonstrating that elections have a strong effect on responsive presidential behavior (Stimson et al. 1995; Jacobs and Shapiro 2000). Moreover, the Prior Vote Hypothesis (past election results should be negative) is also proven accurate as both models in Table 1 reveal that the percentage of the 
popular vote from the president's previous election is negative and not statistically significant. ${ }^{21}$

However, contradicting our expectations in Second Term Hypothesis, even though they cannot be reelected, second term presidents (Eisenhower, Nixon, Reagan, and Clinton) are significantly more likely to anticipate public opinion than first term presidents. ${ }^{22}$ Given that the electoral incentive dissipates after presidents are reelected, this finding runs against the findings from Canes-Wrone (2006) and Canes-Wrone and Shotts (2004). These works may have overlooked the important legacy and party attachment elements to second term presidencies, where presidents have been shown to be congruent with public opinion in their second terms as a result of wanting to cement a popular legacy and desiring to assist in the election of their party in the subsequent election (Rottinghaus 2006).

We also suggested in the Issue Importance Hypothesis that more salient issues should produce more presidential success in anticipating latent opinion. This expectation is demonstrated accurate in Model 2 in Table 1 (which takes into account several specific issues), where the coefficient for salience is positive and significant (.005). Consistent with Key's (1964) observations, presidents surmise the future salience of a particular policy issue to determine whether or not to make congruent statements with public opinion. This also confirms Geer's (1996) theoretical argument that presidents governing in an environment replete with polls would practice "Wilsonian" leadership by taking popular positions on more salient issues. This also implies, as expected, that presidents are interested in appeasing the public in terms of the valence of issues as well as on the substance of issues. Yet, the effect is somewhat small, implying that salience is only weakly related to future congruent position taking.

Additionally, turning to the Issue Cost Hypothesis, on particular issues judged to invoke "costs" from the American public (such as tax policy, welfare spending and budget spending), we find that this condensed variable is not a substantive or significant predictor of presidential anticipatory behavior. The "Issue Costs" variable in both models of Table 1 suggests that on those issues that may register a larger cost to the American public, presidents are not more likely to anticipate public opinion in a direction favoring higher costs judged by the lack of significance of the variable $(.024, .079$ in Models 1 and 2). In both instances, the president is insuring that the public's well being is catered to by not enacting burdensome public policy, consistent with our broad expectations about presidents anticipating opinion on more important issues. Yet, "doorstep" issues (those issues suggested to be closer to the people, especially involving personal finances, welfare and health care) were not consistently significant in producing presidential anticipation 
of latent opinion. In neither model did these issues become statistically significant.

\section{Conclusion}

Consistent with Woodrow Wilson's arguments discussed above, our findings reveal several dimensions on how presidents relate to the future, predicted political environment and has extended the literature on presidential congruency with public opinion. In particular, the data indicate that all of our predicted election-based variables adhere to expectations. Presidents are more successful at anticipating opinion when elections are closer, during a presidential election year but not reflective of the popular vote from the previous election. These findings are not surprising because anticipation of public opinion is inherently a forward looking objective, reflecting Key's (1964) "electoral reprisal" argument and a wealth of presidential scholarship that anchors presidential decision making to upcoming elections. These findings also reveal that the "electoral connection" appears to be robust in relating to a "permanent campaign" strategy of campaign-style governing (Blumenthal 1980; Tenpas 2003; Heith 2003; Doherty 2007). Building on these findings of strategic resource allocations, our study extends empirical investigations of the "permanent campaign" to include rhetorical policy actions. These conclusions demonstrate a reoccurring (and often successful) strategy by presidents (in their first and second terms) to engage in permanent campaigning by continuously responding to public preferences in a manner prescribed during the campaign season.

In addition to demonstrating the power of elections in shaping presidential behavior, in the present data we also expand our understanding of how and when presidents interpret the prospect of future public support. The evidence suggests that, in anticipating public preferences by introducing new policies into the agenda, current popularity does not seem to have an effect. Interestingly, Key (1964) does not mention popularity as a resource in anticipation of latent opinion, rather his focus is on presidents understanding and anticipating opinion at times of reelection. These findings also help to explain presidential agenda setting behavior and provide insight into when we might expect new presidential policy proposals. Based upon these findings, presidents tend to look outward at the political environment they face rather than inward (at popularity) in anticipating reactions to new policy agendas. Specifically, we discover that presidents are more likely to follow public preferences (or what they presume are public preferences) on higher salience issues, a finding which reinforces scholarly thinking about leadership on "easy" issues (Bailey et al. 2003) and similar to Geer's fear that 
frequent access to public opinion polls establish "more demagogues and fewer leaders" $(1996,115)$.

In circumstances where presidents have a choice of whether or not to follow to public opinion, White Houses go for the "easy" sell-they take positions favored by public opinion in instances where the mass public cares about the issue. For instance, we find presidents unlikely to anticipate majority public preferences on issues where taking a position may impose a "cost" on voters' pocketbooks. This confirms findings from the congressional literature that argues that legislators work to reduce the costs for their constituents (Arnold 1990). Similarly, we find presidents strongly seek to follow public preferences when the issues are important issues to the public. The realization that choosing issues on the wrong side of an attentive public, as implied by Key's interpretation of latent opinion, compels presidents to make sure that the public's core needs are satisfied and policy choices do not impose additional costs on the voters.

\section{NOTES}

${ }^{1}$ See Cook and Manza (2002) and Burstein (2003) for excellent summaries of this body of work.

${ }^{2}$ Our simple argument here is that presidents anticipate public opinion out of a desire to be congruent with public opinion. It could also be the case that presidents are pandering to the public or are attempting to shape public opinion before opinion is registered (see Jacobs and Shapiro 2000). Our data do not allow for a test of these theories and examining presidential motivations of pandering or shaping public opinion is difficult. Therefore, in this article, we adhere to factual findings and only speculate about the degree that presidents are pandering or shaping opinion.

${ }^{3}$ In this article, we test one proposition of opinion latency (the "estimation of the direction of majority sentiment") and leave the supplemental questions Key poses (such as predicting "the estimation of what sectors of society, influential and noninfluential, will have opinions" or "whether an issue will command the attention of a large public") aside (see Key 1964, 266). I do this because these questions speak to the makeup of latent opinion rather than the impact of latent opinion, as is the question in this paper.

${ }^{4}$ To measure salience, we use Gallup's measure of "issue importance." The exact wording of the Gallup organization's question is: "What do you think is the most important problem facing this country today?" When appropriate, other answers to similar questions were recorded, as long as the questions allowed for (1) open ended to the respondent and (2) requested only one (rather than two or three) "top issues" were coded. This preserved the spontaneous and singular "problem" nature of the issue in question.

${ }^{5}$ Concurrent with Arnold (1993), we isolated those issue mentions where the president endorsed, supported or introduced a potential new "cost" to the voters in three issue areas: taxes, budget and health care and Social Security. On issues of taxes, tax credits or tax cuts were coded as reducing tax burdens while increasing taxes on BTU's, estate taxes or capital gains were counted as a tax increase. On issues of the budget, references to "balanced" budgets or reducing debt or expenditures were coded as reducing the "cost" 
of the issue while any reference to a budget expenditure was coded as increasing the "cost." On health care and Social Security, any references to increasing taxes on Social Security, raising the retirement age, funding a particular diseases (such as cancer or AIDS) or nationalizing health care were all considered an increase in the "cost" of the issue. The variable is a dummy variable, with "cost" issues is coded as " 0 " and " 1 " if a cost was not incurred.

${ }^{6} \mathrm{~A} 4 \%$ random sample was decided upon since it would yield a manageable number of statements to match with opinion polling.

${ }^{7}$ This process was thought to be the most systematic, consistent and relatively simple manner in which to select a case on the page. The Public Papers themselves are organized chronologically, but there seems to be no logical way that there would be a consistent bias in selecting the first such statement on the page in question. Although the placement of the page break from page to page in the president's speech is not technically or purely random, it is various enough to not present any consistent selection bias.

${ }^{8}$ This process also required excluding several types of statements that violated this general principle. Generally, statements that were not coded include those that were too vague, procedural statements, ceremonial statements, political speculation, economic predictions, observations on the general state of the economy, conditional statements ("might" or "maybe" or "considering") or personnel decisions.

${ }^{9}$ While this "matching" approach to measuring opinion-statement congruency is not perfect, it has been utilized by several scholars in important works in examining opinionpolicy congruence (see Page and Shapiro 1983; Page and Shapiro 1992; Jacobs and Shapiro 1995; Jacobs and Shapiro 1997).

${ }^{10}$ Essentially, the policy issue had to be specific to the poll (e.g., "we need to reduce the deficit" or "I support a raise in the minimum wage") rather than vague (e.g., "we need to work for peace in the world" or "we need to help the neediest people with our programs" or "we need to make government smarter") and/or make clear (or reasonably clear) the president's advocacy of a particular policy approach. However, if the intended effect or assisted group was vague but was attached to a policy, the president was coded as supporting the policy (e.g., "we need to pass my health care bill to protect our kids"). At the sentence level, if a sentence referred to several advantages or several reasons for presidential support in a statement, the first such advantage listed was coded as the dependent variable and the additional advantages within the sentence were counted as individual statements (on the assumption that the president would desire to individually enumerate them). For instance, if the president said, "Our tax bill will reduce the deficit, give tax cuts to the middle class and remove the capital gains restrictions," the tax bill "reducing the deficit" was the coded statement and the remaining two were counted as statements on page. Similarly, at the paragraph level, if the president listed ten separate advantages (or features) of the same bill, the first sentence was coded and the remaining nine were counted as assertions. The line drawn here is between specific issue and vague solution in order to capture the most specific issue possible.

${ }^{11}$ The percentage of those that responded "don't know" or "not sure" to each poll question was also recorded. In separate models run (but not shown here), the findings of presidential anticipation with those responding "don't know" or "not sure" reaveraged into the overall percentages revealed no significant changes in the outcomes.

${ }^{12}$ Page and Shapiro (1983) argue that a one-year lag in opinion and policy congruence is a reasonable time interval and base their results on this thinking (see page 177). Page, Shapiro, and Dempsey (1987) also discover that changes to presidential approval take an average of five to ten months to take effect, providing support for our modeled time lag. Further, in offer an "after only" design that does not attempt to argue for persua- 
sion (i.e., causality) effects (merely suggesting congruent or non-congruent position taking) we are safe in assuming that our measure of opinion after the president's statement is the first polled opinion on that matter (see Sigelman and Rosenblatt 1996).

${ }^{13}$ Cohen and Hamman (2003) describe this phenomenon of searching for data on public preferences after the president spoke on an issue (in their case, State of the Union addresses) "issue installation" (see pages 145-148). They rely on public mood data, not direct measures of public opinion.

${ }^{14}$ Key does argue that speeches are not necessarily sufficient to arouse public attention but speeches combined with policy or reflective of objective concerns is sufficient. He argues, "talk, even from the most conspicuous sources, is not enough to arose widespread attention or demand. Propaganda seems to be most effective when reinforced by objective conditions" $(1964,285)$. Since most of the speeches made by the president in our measure of "anticipation" are either new policies or the president taking a new position on a real event, this condition is satisfied.

${ }^{15}$ The key here is that we are measuring polled opinion only after the president speaks. This accounts for the relatively low number of yielded cases from our original sample of 1,976 statements. Our design adds to the uniqueness of this relationship because we have a valid measure of how popular the issues was after the president discussed it publicly but with no prior baseline of opinion. There were 944 instances of "congruence" before the president spoke.

${ }^{16}$ In $75 \%$ of the cases where public opinion data was found only after the president's statement was made, presidential statements matched the position favored by a majority of the public. This $75 \%$ figure is derived from the total number of statements of which there are valid opinion above 51\% approving of the president's position after the president's statement (173) out of the total cases where there was any poll-matched statement after the president's statement (230). This measure excludes the cases for which there was only matched opinion either only before the statement. The Chi Square (19.042) and Gamma statistic (.283) are both statistically significant at $\mathrm{p}>.01$. Richard Nixon (84.3\%) and Bill Clinton (85\%) were the highest, while Gerald Ford (33.3\%) and Jimmy Carter (52.9\%) were the lowest.

${ }^{17}$ Table 1 presents the full model including all control variables. We also include two specifications: one including several specific issues and one including the "doorstep" measure more broadly defined. These are reported in Model 1 and Model 2. In alternative models run with a non-monotonic specification for popularity (comporting with CanesWrone and Shotts (2004), the effect of popularity in instances of first or second half of terms were still negative and not significant.

${ }^{18} \mathrm{~A}$ Heckman specification could be appropriate here because, although we randomly select and directly observe the president's speeches and the public opinion polling associated with each statement, we do not observe the public opinion polls for all presidential statements (or all issues). Specifically, we only observe public opinion polls for those statements that we randomly sample, not the universe of public opinion polls. That is, there is a degree of "self selection" in that pollsters only poll on particular issues (rather than all or a random sample of issues), making sample selection bias a possible problem with traditional OLS (Heckman 1979). Yet, the insignificance of the lambda statistic across several specifications of the selection equation leads us to reject this model.

${ }^{19}$ This coefficient is strong and significant in both models in Table 1. The assumption is that we need a counter measure to control presidential position taking on all issues versus only select issues the White House cares about greatly. If the issue was mentioned in the president's annual message, we presume it is part of his core agenda (Cohen 1999). 
${ }^{20}$ "Election upcoming" is a countdown variable, coded as the number of years until the next election.

${ }^{21}$ President Ford's ascendancy to office did not provide a popular vote score, so as a proxy for his two years in office we used President Nixon's 1972 election results.

${ }^{22}$ Alternate models run with each of the presidents as a dummy variable demonstrated that none of the presidents as individuals presented a statistically significant success at anticipating public opinion, therefore these variables were excluded from the final model.

\section{REFERENCES}

Arnold, R. Douglas. 1990. The Logic of Congressional Action. New Haven, CT: Yale University Press.

Arnold, R. Douglas. 1993. Can Inattentive Citizens Control Their Elected Representatives? In Congress Reconsidered, 5th ed., eds. Lawrence C. Dodd and Bruce I. Oppenheimer. Washington, DC: CQ Press.

Bailey, Michael, Lee Sigelman, and Clyde Wilcox. 2003. Presidential Persuasion on Social Issues: A Two-Way Street? Political Research Quarterly 56(1):49-58.

Blumenthal, Sidney. 1980. The Permanent Campaign: Inside the World of Elite Political Operatives. Boston: Beacon Press.

Brace, Paul, and Barbara Hinckley. 1992. Follow the Leader: Public Opinion Polls and the Modern Presidents. New York: Harper Collins Publishers.

Burns, James MacGregor. 1978. Leadership. New York: Perennial Books.

Burstein, Paul. 1998. Bringing the Public Back In: Should Sociologists Consider the Impact of Public Opinion on Public Policy? Social Forces 77:27-62.

Burstein, Paul. 2003. The Impact of Public Opinion on Public Policy: A Review and an Agenda. Political Research Quarterly 56(1):29-40.

Canes-Wrone, Brandice. 2001. The President's Legislative Influence from Public Appeals. American Journal of Political Science 45(2):313-329.

Canes-Wrone, Brandice. 2004. The Public Presidency, Personal Approval Ratings, and Policy Making. Presidential Studies Quarterly 34(3):477-492.

Canes-Wrone, Brandice. 2006. Who Leads Whom? Presidents, Policy, and the Public. Chicago: University of Chicago Press.

Canes-Wrone, Brandice, Michael C. Herron, and Kenneth W. Shotts. 2001. Leadership and Pandering: A Theory of Executive Policymaking. American Journal of Political Science 45:532-550.

Canes-Wrone, Brandice, and Kenneth W. Shotts. 2004. The Conditional Nature of Presidential Responsiveness to Public Opinion. American Journal of Political Science 48(4):690-706.

Cohen, Jeffery E. 1995. Presidential Rhetoric and the Public Agenda. American Journal of Political Science 39(1):87-107.

Cohen, Jeffery E. 1999. Presidential Responsiveness and Public Policy-Making: The Public and the Policies that Presidents Choose. Ann Arbor: University of Michigan Press.

Cohen, Jeffery E., and John A. Hamman. 2003. Presidential Ideology and the Public Mood. In In the Public Domain: Presidents and the Challenges of Public Leadership, eds. Lori Cox Han and Diane J. Heith. Albany: State University of New York Press. 
Conley, Patricia Heidotting. 2001. Presidential Mandates: How Elections Shape the National Agenda. Chicago: University of Chicago Press.

Doherty, Brendan J. 2007. Elections: The Politics of Permanent Campaign: Presidential Travel and the Electoral College, 1977-2004. Presidential Studies Quarterly 37(4): 749-773.

Edwards, III, George C., William Mitchell, and Reed Welch. 1995. Explaining Presidential Approval: The Significance of Issue Salience. American Journal of Political Science 39:108-134.

Edwards III, George C., and B. Dan Wood. 1999. Who Influences Whom? The President, Congress and the Media. American Political Science Review 93(2):327-344.

Eisinger, Robert M. 2002. The Evolution of Presidential Polling. Cambridge: Cambridge University Press.

Elling, Richard C. 1982. Ideological Change in the United States Senate: Time and Electoral Responsiveness. Legislative Studies Quarterly 7:75-92.

Erikson, Robert S., Michael B. MacKuen and James A. Stimson. 2002. The Macro Polity. Cambridge: Cambridge University Press.

Fording, Richard C. 1997. The Conditional Effect of Violence as a Political Tactic: Mass Insurgency, Welfare Generosity, and Electoral Context in the American States. American Journal of Political Science 41(1):1-29.

Geer, John G. 1996. From Tea Leaves to Opinion Polls: A Theory of Democratic Leadership. New York: Columbia University Press.

Heckman, James J. 1979. Sample Selection Bias as a Specification Error. Econometrica 41(1):153-61.

Heith, Diane J. 2004. Polling to Govern. Palo Alto, CA: Stanford University Press.

Jacobs, Lawrence R., and Robert Y. Shapiro. 1999. Lyndon Johnson, Vietnam, and Public Opinion: Rethinking Realists' Theory of Leadership. Presidential Studies Quarterly 29:592-616.

Jacobs, Lawrence R., and Robert Y. Shapiro. 2000. Politicians Don't Pander: Political Manipulation and the Loss of Democratic Responsiveness. Chicago: University of Chicago Press.

Jacobs, Lawrence R., and Robert Y. Shapiro. 2002. Politics and Policymaking in the Real World: Crafted Talk and the Loss of Democratic Responsiveness. In Navigating Public Opinion: Polls, Policy and the Future of American Democracy, eds. Jeff Manza, Fay Lomax Cook, and Benjamin I. Page. New York: Oxford University Press.

Jacobs, Lawrence R., and Robert Y. Shapiro. 1995. The Rise of Presidential Polling: The Nixon White House in Historical Perspective. Public Opinion Quarterly 59:163195.

Kelley, Jr., Stanley. 1983. Interpreting Elections. Princeton, NJ: Princeton University Press.

Kennedy, Peter. 1998. A Guide to Econometrics, 4th ed. Cambridge, MA: MIT Press.

Kernell, Samuel. 1978. Explaining Presidential Popularity. American Political Science Review 72:506-522.

Kernell, Samuel. 1997. Going Public: New Strategies of Presidential Leadership. Washington, DC: CQ Press.

Key, V.O., Jr. 1964. Public Opinion and American Democracy. New York: Alfred A. Knopf.

Kuklinski, James H. 1978. Representativeness and Elections: A Policy Analysis. American Political Science Review 72(1):165-77. 
Light, Paul C. 1999. The President's Agenda: Domestic Policy Choice from Kennedy to Clinton. Baltimore, MD: Johns Hopkins Press.

Mansbridge, Jane. 2003. Rethinking Representation. American Political Science Review 97(4):515-528.

Manza, Jeff, and Fay Lomax Cook. 2002. A Democratic Polity? Three Views of Policy Responsiveness to Public Opinion in the United States. American Politics Research 30(6):630-677.

Mayhew, David R. 1991. Divided Party Control: Does it Make a Difference? PS: Political Science and Politics 24:637-640.

Monroe, Alan D. 1998. Public Opinion and Public Policy, 1980-1993. Public Opinion Quarterly 62:6-28.

Neustadt, Richard E. 1990. Presidential Power and the Modern Presidents. New York: Free Press.

Page, Benjamin I. 1978. Choices and Echoes in Presidential Elections: Rational Man and Electoral Democracy. Chicago: University of Chicago Press.

Page, Benjamin I. 2002. The Semi-Sovereign Public. In Navigating Public Opinion: Polls Policy and the Future of American Democracy, eds. Jeff Manza, Fay Lomax Cook, and Benjamin I. Page. New York: Oxford University Press.

Page, Benjamin I., and Robert Y. Shapiro. 1983. Effects of Public Opinion on Policy. American Political Science Review 77(1):175-90.

Rottinghaus, Brandon. 2006. Rethinking Presidential Responsiveness: The Public Presidency and Rhetorical Congruency, 1953-2001. Journal of Politics 68(3):720-732.

Sigelman, Lee, and Alan Rosenblatt. 1996. Mythological Considerations in the Analysis of Presidential Persuasion. In Political Persuasion and Attitude Change, eds. Diana C. Mutz, Paul M. Sniderman, and Richard A. Brody. Ann Arbor: University of Michigan Press.

Stimpson, James A., Michael B. MacKuen, and Robert S. Erikson. 1995. Dynamic Representation. American Political Science Review 89(3):543-564.

Tenpas, Katherine Dunn. 2003. Presidents as Candidates: Inside the White House for the Presidential Campaign. New York: Routledge.

Thomas, Martin. 1985. Election Proximity and Senatorial Roll Call Voting. American Journal of Political Science 29(1):96-111.

Wilson, Woodrow. 1952. Leaders of Men, ed. T.H. Vail Motter. Princeton, NJ: Princeton University Press.

Wlezien, Christopher. 1995. The Public as Thermostat: Dynamics of Preferences for Spending. American Journal of Political Science 39(4):981-1000.

Wlezien, Christopher. 1996. Dynamics of Representation: The Case of U.S. Spending on Defense. British Journal of Political Science 26(1):567-588.

Zaller, John R. 2003. Coming to Grips with V.O. Key's Concept of Latent Opinion. In Electoral Democracy, eds. George Rabinowitz and Michael C. MacKuen. Ann Arbor: University of Michigan Press. 